\title{
Software Defined Network-based Scalable Resource Discovery for Internet of Things
}

\author{
Mahbuba Afrin ${ }^{1}$, Redowan Mahmud ${ }^{1}$ \\ ${ }^{1}$ Department of Computer Science and Engineering, University of Dhaka, Bangladesh, \\ email: m.afrin.ritu@gmail.com, ratul06oct@gmail.com
}

\section{Abstract}

Geo-distributed and heterog eneous Internet of Things (IoT) devices can gener ate huge amoun $t$ of data. Inefficien $t$ manag emen $t$ of IoT-data promotes netw ork cong estion and increases computa tional overhead on the data-processing entities. Traditional netw orking architecture, that is lack of functional abstr action and monitoring capabilities, often fails to meet the dynamics of IoT. Softw are Define Network (SDN) can be a viable alterna tive of the traditional netw orking architecture while dealing with IoT. In SDN, manag ement, monitoring and context sensing of the connected componen ts are simplifie and can be customized. In this paper, SDN-sensed contextual information of differen $t$ componen ts (computa tional en tities, netw ork, IoT devices) are combined together to facilita te scalable resource discovery in IoT. The proposed policy targ ets balanced processing and cong estion-less forwarding of IoT-data. Through simulation studies, it has been demonstr ated that the SDN-based resource discov ery in IoT outperf orms the traditional netw orking based approaches in terms of resource discov ery time and Quality of Service (QoS) satisf action rate.

Received on 09 April 2017; accepted on 13 July 2017; published on 25 September 2017

Keywords: Internet of Things, Resource Discovery, Softw are define netw ork, Scalability, Service QoS

Copyright (C) 2017 Mahbuba Afrin and Redowan Mahmud, licensed to EAI. This is an open access article distributed under the terms of the Creative Commons Attribution license (http://creativecommons.org/licenses/by/3.0/), which permits unlimited use, distribution and reproduction in any medium so long as the original work is properly cited.

doi:10.4108/eai.25-9-2017.153149

\section{Introduction}

In recen $t$ years, the Internet of Things (IoT) has drawn significa $t$ research interest. Due to rapid enhancemen $t$ in hardw are and communica tion technol ogy, it is predicted that by 2020, there will be more than 50 billion active IoT devices [1]. IoT devices are geodistributed, energy constr ained and heterog eneous. The configu ations, applicability and sensing frequency of IoT devices are also diversified

Most of the IoT devices participa te in real-time data sensing. As a consequence, the devices can generate huge amount of data within a minimal time. When a large number of IoT devices send data simultaneousl y tow ards the computa tional entities (e.g. Cloud, Fog nodes, Edge servers), it is more likel y to crea te netw ork congestion. Besides, random placemen $t$

\footnotetext{
^ Please ensure that you use the most up to date class file available from EAI at http://doc.eai.eu/publications/transactions/ latex/

*Corresponding author. Email: m.afrin.ritu@gmail.com
}

of IoT-data can increase processing overhead on the computational entities. In such scenario, efficiency of the under lying netw ork in managing incoming IoTdata (data processing, data forwarding) is very crucial. However, due to lack of functional abstraction and inability in monitoring internal operations of the connected componen ts (IoT devices, computa tional entities), the traditional netw orking architecture is not suitable for efficient IoT-data manag emen t. In this case, Softw are Define Netw ork (SDN) can be adopted to overcome the shortcomings of traditional netw orking architecture in respect of IoT [2].

SDN is a very recen $t$ innovation in netw orking technology that operates through softw are system in place of specialized and dedica ted hardw are. It offers programmability of netw orking elemen ts by decoupling netw ork control plane and data forwarding plane [3]. In SDN, there exists a centralized entity that perceiv es the topol ogy and status of the netw ork. Based on perception, the centralized controller entity determines the data forwarding rules and notifie the rules to the data forwarding entities. Through abstr action of lower level 
netw orking functionalities, SDN can set up, administrate, alter, and manag e netw ork beha vior dynamicall $\mathrm{y}$. In different computing paradigms (e.g. Cloud computing, Mobile edge computing), SDN based solutions have been explored extensiv ely to meet auto-mated, on-demand service requests, handle mobility issues, ensure netw ork reliability, etc. [4]. SDN-based solutions promotes virtualiza tion of netw ork, ensures flexibilit in resource utiliza tion, monitors internal operations of the connected componen ts, senses contextual information, minimizes both capital and operational expenses. Although, networking among the sensors is the fundamen tal factor for IoT [5], SDN-based solutions for IoT have not been enlightened significa tly. From the perspectiv e of IoT, SDN-based solutions can play vital roles in resource discov ery and load balancing.

Gener ally, resource discovery in IoT refers to fin appropria te resources for processing IoT-data and its associa te routing path to forward the data. In traditional networking architecture, the computational entities for processing IoT-data and the associa te connections are predefine and static. Theref ore, traditional static netw ork architecture can not cope with the increasing number of IoT devices and their uncertain data load. As a resul t, QoS degr adation in terms of netw ork bandwid th and service deliv ery is widel y observ ed. Taking cognizance of this fact, we investig ate how SDN-based solutions can facilita te resource discovery in IoT. The proposed SDN-based solution incorporates contextual information from three differen $t$ aspects (computa tional entities, netw ork, IoT devices) while dealing with resource discov ery in IoT to facilita te flexibl data processing and congestion-less data forwarding. Besides, the proposed policy ensures dynamic manag emen $t$ of IoT-data in SDN that can be scalable to certain exten $t$ according to the situa tion.

The major contribution of the paper are listed as:

- SDN-based solution for scalable IoT-resource discovery to facilita te unin terrupted data processing and data forwarding.

- Expl ored the applicability of SDN-sensed contextual information in managing uncertain load of IoT-data.

- Comparative study between SDN-based IoT resource discovery and traditional static netw ork based approach in terms of resource discovery time and QoS satisf action rate.

In the following section, several rela ted works in this fie $\mathrm{d}$ are highlighted (Section. 2). In Section. 3 and 4 the system model and SDN-based IoT-resource discovery are discussed respectiv ely. In Section. 5 perf ormance evaluation is demonstr ated. Section. 6 concludes the paper.

\section{Related Works}

Several research works on SDN has already been conducted in different areas of computation and netw orking. In [6], authors design a SDN-supported cloud computing environmen $\mathrm{t}$ through OpenFLow switches and controllers. They extend the features of OpenFLow controller in order to facilita te load balancing, less energy usage, and service monitoring. Besides, a queuing model is developed to claim the feasibility of the system. The SDN based solution aims at providing QoS satisfie cloud computing services.

In [7] some poten tial architectures of SDN-based Mobile Cloud has been proposed. The authors of the paper focus on iden tifying basic componen ts of SDN-based Mobile Cloud that can deal with mobility and uncertain network status. Several frequency selection methods for data transmission have also been discussed. The feasibility of the SDN-based solution has been highlighted in terms of high packet deliv ery rate and system overhead.

The authors in [8] argued that with dense depl oymen $t$ of mobile devices and limited netw ork bandwid th, it becomes difficult to assign radio resources for processing service requests. Besides, manag emen $t$ of interference and load balancing between base stations get tough. To overcome these issues, authors propose a softw are define radio access layer named "SoftRAN". It works as the centralized control plane for radio access netw ork. According to the authors, SoftRAN can efficiently handle load distribution, manag e interf erence within the netw ork maximize the netw orking throughput.

In respect of scalability in SDN, the authors of [9], claimed that SDN scalability is free from inheren $t$ bottleneck. In that paper, the scalability of SDN controller has been discussed in details. Besides, the authors investig ate the scalability in SDN in terms of overhead and fault toler ance. Since SDN reduces netw ork progr amming and manag emen $t$ complexity, SDN enhances the level of flexibilit to accommoda te netw ork progr amming and manag emen $t$ at any scale.

The impact of SDN in IoT has also been explored in several research works. In [10] a softw are define framew ork is proposed that simplifie manag emen $t$ of IoT-driv en process and deals with dynamic challenging aspects of IoT in terms of forwarding, storing and securing sensed IoT-data. The framew ork integr ates the softw are define netw ork, softw are define storage, and softw are define security into a single softw are define based control model.

In [11] authors represen $t$ a softw are-define IoT system for controlling f ow and mobility in multi-netw orks named "UbiFl ow". UbiFl ow facilita tes controllers entity to be placed distributiv ely so that urban-scale SDN can be divided into different geographic partitions. In 
this case, a hash-based distributed overlay structure helps to main tain netw ork scalability and consistency . Fault toler ance and load balancing are also handled by UbiFl ow. Besides, it provides visibility over under lying netw ork and optimizes the selection process of access poin ts within multi-netw orks so that QoS satisfie IoT dataf ow can be ensured.

However, in the aforemen tioned works, the impact of SDN-sensed contextual information in IoT resource discovery has not been enlightened. Resource discov ery plays an importan $t$ role in not only ensuring QoSsatisfie processing of IoT-data but also managing netw ork from being congested due uncertain load. Therefore, the paper aims at SDN-based resource discovery for IoT so that scalability in resource discovery for IoT-data processing and forwarding can be ensured.

\section{System Model}

IoT-devices are geo-distributed and heterog eneous in terms of data sensing frequency and applica tionspecific tion. Due to energy constraint, IoT-devices cannot process any sensed data but using communication protocols like Constrained Applica tion Protocol (CoAP), Simple Netw ork Manag emen t Protocol (SNMP), etc. can forward the sensed data towards Cloud or Fog for further processing. How ever, here we assumed that, the IoT-devices and the computational entities can interact through SDN.

Unlike traditional static netw orking architecture (as shown in Fig. 1.a), in SDN (as shown in Fig. 1.b), data forwarding plane is decoupled from the controller plane. Here, a Centralized Controller componen $\mathrm{t}(\mathrm{CC})$ determines the routing path and data forwarding rules. The other netw orking entities like switches, gateways, access points, base stations, etc. forwards the data according the guidelines of the CC.

In order to identify the efficient data routing path and computa tional entity, the $C C$ senses the contextual information and monitors the internal operations of netw ork, computa tional entities and IoT devices. In general, contextual information provides enriched perception regarding differen $t$ system componen ts [12]. Here, the contextual information includes:

- Curren t traffic load (netw ork throughput) on different routing paths.

- Curren t data processing load (size of queued data) on each computa tional entity.

- Data sensing frequency (data transmission rate) of IoT devices.

As the componen ts of the modelled system interacts with each other through SDN, it is possible to tarck the context of each componen ts. Reference of several

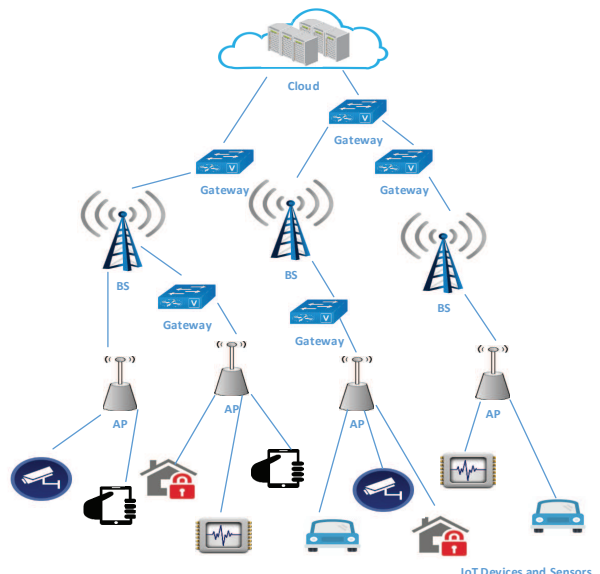

(a) Traditional sta tic netw ork

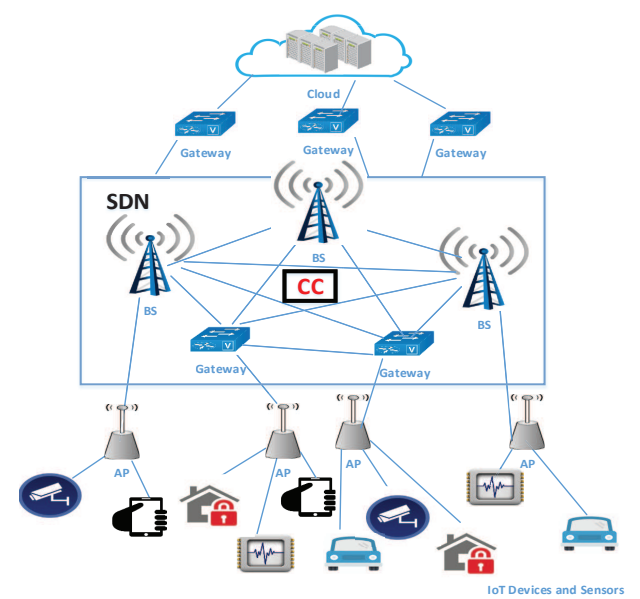

(b) SDN-enabled netw ork

Figure 1. Networking architecture for loT.

context-sensing framew ork for SDN is available in the liter ature [13] [14]. Any of the framew orks can be applied to track the aforementioned contextual information of the computa tional entities, under lying netw ork and IoT devices. The sensed contextual information helps CC to perceiv e the whole system efficiently and enhance the visibility over each of the componen ts.

Due to softw are define architecture, SDN can dynamicall y activ ate any idle computa tional entity and routes tow ards the entity whenev er the curren $t$ system model becomes unable to meet the service demand. Moreover, in an SDN-based system, an IoT-device is unaware about the computational entity where associate IoT-data is going to be processed. In consequence, the system becomes able to provide virtualiza tion in processing IoT data and can be manag ed according to the dynamics of the environmen t. Hence, an SDN-based system supports scalability to a certain exten t. Conversel $y$, in the traditional static netw ork architecture, IoT-data cannot be migrated to other computational 
en tity as it does not provide any virtualized settings. As a resul $t$ it becomes very difficul t to achiev e scalability in the traditional netw ork.

Necessary notation for modelling the system has been provided in Table. 1

Table 1. Notations

\begin{tabular}{|c|c|}
\hline Symbol & Definitio \\
\hline$E$ & Set of all com puta tional en tities. \\
\hline$\alpha_{e}$ & $\begin{array}{l}\text { Data processing capacity of computa tional } \\
\text { entity } e, e \in E\end{array}$ \\
\hline$\phi_{e}$ & $\begin{array}{l}\text { Curren t data processing load on computa- } \\
\text { tional entity } e, e \in E\end{array}$ \\
\hline$P$ & Set of all comm unica tion paths. \\
\hline$P_{e}$ & $\begin{array}{l}\text { Set of all comm unica tion paths to compu- } \\
\text { tational entity } e, e \in E ; P_{e} \subset P\end{array}$ \\
\hline$\beta_{p}$ & $\begin{array}{l}\text { Data transmission capacity of comm unica- } \\
\text { tion path } p, p \in P\end{array}$ \\
\hline$\omega_{p}$ & $\begin{array}{l}\text { Curren t data transmission load of commu- } \\
\text { nica tion path } p, p \in P\end{array}$ \\
\hline$\lambda_{n}$ & Data transmission rate of any IoT device $n$. \\
\hline$\mu_{n}$ & Sensed da ta by any IoT device $n$. \\
\hline
\end{tabular}

\section{SDN-based loT-resource discovery}

The proposed SDN-based IoT-resource discover policy executes in the CC. Whenever an IoT-device $n$ sensed any data $\mu_{n}$ from the external environmen $\mathrm{t}$, it forwards the data $\mu_{n}$ through SDN to CC. Besides, the contextual information of IoT-device $n$ regarding its data transmission rate $\lambda_{n}$ is also sent to CC. Based on the receiv ed information, $C C$ runs the DiscoverResources proced ure as shown in Algorithm. 1.

The DiscoverResources proced ure is consist of four basic steps. The steps can be describes as follows:

1. At firs, for each of the computa tional entity (line 4 ), it is checked whether the inclusion of $\mu_{n}$ to its curren $t$ data processing load exceeds the capacity of the corresponding computa tional entity (line 5). If it satisfies then the computa tional entity with minim um data processing load is selected as the targ et entity for processing $\mu_{n}$ (line 6-8). This approach can be termed as the best-fi selection of computa tional entity.

2. Later, from the available routing paths the suitable routing path towards the selected computa tional entity is iden tifie (line 10-13). In this case, the firs route is selected that cannot be congested due to per unit time data transmission from the IoT device $n$ (line 11). This is considered as the firs -fi selection of the routing path.

3. In this step the sensed data $\mu_{n}$ of IoT-device $n$ is forwarded towards the selected computa tion entity through a congestion-less routing path (line 14-16).

4. If no feasible computational entity or routing path is found, CC can dynamicall y initia te any idle

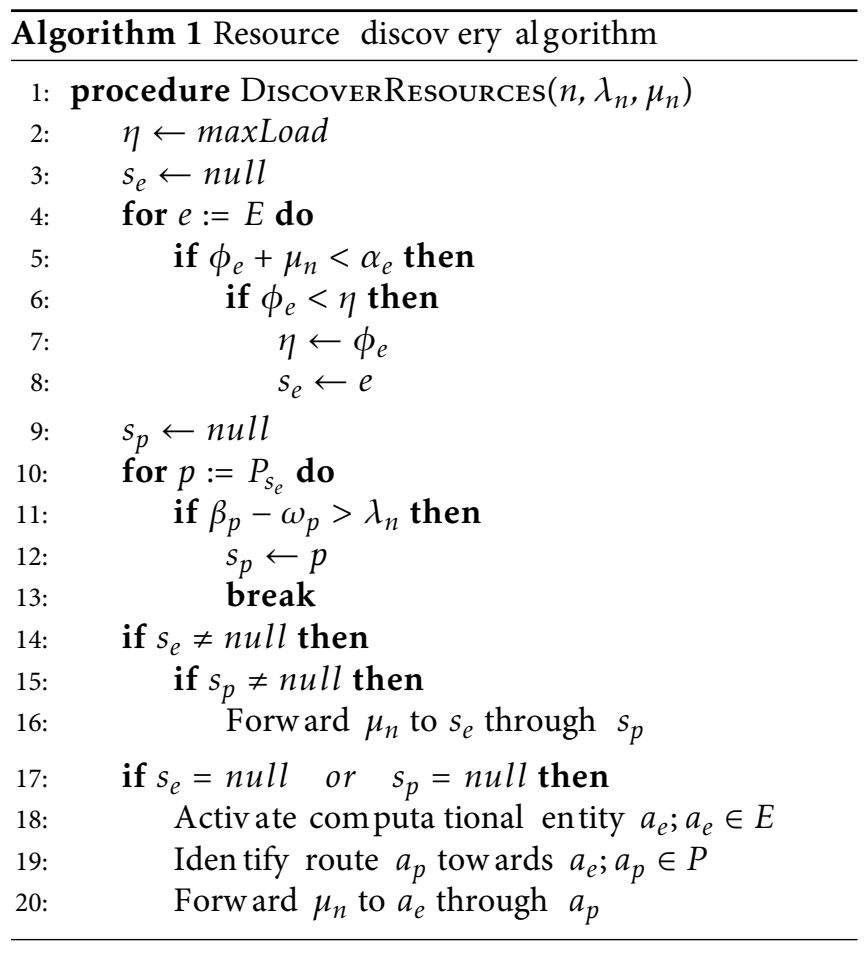

computa tional entity and iden tify route towards the entity so that the sensed data $\mu_{n}$ can be forwarded for processing.

The DiscoverResources proced ure combines best-fi and firs -fi selection approach (step 1-2) within it. Gener ally, the complexity of this algorithm will increase linear ly as the number of computa tional entity increases. However, due to step 1 and 2, it becomes easier to iden tify appropria te computa tional resources and associa ted routing path (step 3). Moreover, due to basic features of SDN, it is also possible to accommoda te increasing service demand to idle computation entities (step 4). As a result, scalability issues in resource discov ery for IoT become attainable.

Since the DiscoverResources proced ure facilita tes resource discovery and scalability, it play crucial role in minimizing resource discovery time and in enhancing QoS satisfaction for increasing number of IoT-service requests. Besides, not only in IoT, the proposed SDN-based approach can be extended to any sort of oper ations [15] where real-time interactions are involved.

\section{Performance Evaluation}

In order to claim the feasibility of the proposed SDNbased IoT-resource discover policy, at firs, the system has been simulated and later the experimen tal resul ts are anal ysed. 


\subsection{Simulation Environment}

The system model has been simulated using iFogSim [16] simula tion toolkit. iFogSim simula tion toolkit has been developed upon the CloudSim framew ork which has been used extensiv ely to simula te Cloud, Mobile Cloud, Vehicular Cloud environmen t.

In the simulation, Fog nodes are considered as the computa tional entities and CC is a specialized Fog node to cond uct basic operations on SDN. In the modelled simulation environmen $t$, IoT-devices can be placed at any location and the devices can ask for processing their sensed data by following poisson distribution.

As the compatible real-world workload is not currently available, in the simulation, syn thetic workload has been used. The workload and modelled system can be easil y re-constructible. Simula tion parameters and units are represen ted in Table. 2.

Table 2. Simulation parameters

\begin{tabular}{|l|l|}
\hline Parameter & Value \\
\hline Sim ula tion Duration & $100 \mathrm{~s}$ \\
\hline Processing capacity of Fog nodes & $20-30 \mathrm{Mbps}$ \\
\hline Service request size & $0.5-1 \mathrm{Mb}$ \\
\hline Link bandwid th capacity & $7-10 \mathrm{Mbps}$ \\
\hline Transmission rate of IoT devices & $2-3 \mathrm{Mbps}$ \\
\hline Service deliv ery deadline & $1-2 \mathrm{~s}$ \\
\hline
\end{tabular}

\subsection{Simulation Results}

The required time for iden tifying suitable computational resources is considered as one of the perf ormance metrics. In order to model resource discovery time Eq. 1 has been applied. Here, the summa tion of data propag ation time $\left(\delta_{t}\right)$ from source IoT device to targ et Fog node and waiting time $\left(v_{t}\right)$ in Fog node has been iden tifie as total resource discovery time $\left(R D_{t}\right)$ for a data processing request.

$$
R D_{t}=\delta_{t}+v_{t}
$$

Fig. 2 depicts that, resource discov ery time for IoT in sta tic netw ork is higher compared to SDN-based policy . Although in SDN-based approach, a certain amoun $t$ of time is required by $C C$ to identify appropria te targ et Fog node and the associa te routing path, the policy helps to reduce data processing waiting time and data propag ation time to a great exten $t$. In fact, the SDN-based solution selects that Fog node and that routing path as processing and comm unica tion medium in which processing load and network congestion is comparatively less. That's why in SDN-based solution resource discovery time gets minimized. Conversel y, in sta tic netw ork based approach neither data processing overhead of Fog nodes nor netw ork cong estion is taken

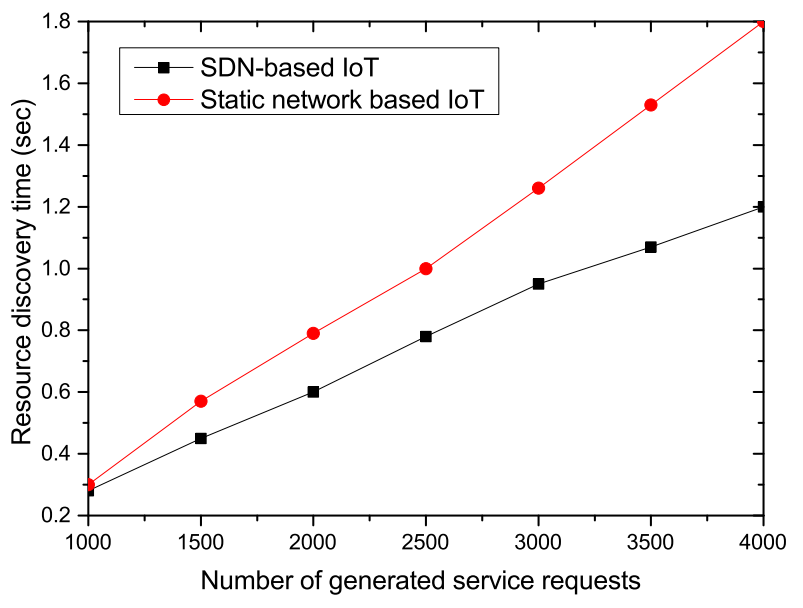

Figure 2. Resource discovery time vs number of service requests

in to accoun $t$. As a result, a high amoun $t$ of time is required for resource discovery.

In addition to resource discov ery time, the percen tag e of QoS-sa tisfie data processing requests is considered as another performance metric. Here, the deadline satisfie service delivery is taken into accoun $t$ as a QoS parameter. A data processing request satisfie QoS when the following condition is satisfied here $\Delta_{t}$ is the service deliv ery deadline, $\tau_{t}$ is the service response time.

$$
\Delta_{t}>\tau_{t}
$$

Fig.3 represen ts that, the percen tage of QoS satisfie service requests in static netw ork decreases significa tly as the number of service requests increases. In SDN-based IoT, as scalable resource discovery for increasing number of service requests is ensured, the percen tage of QoS satisfie service requests always

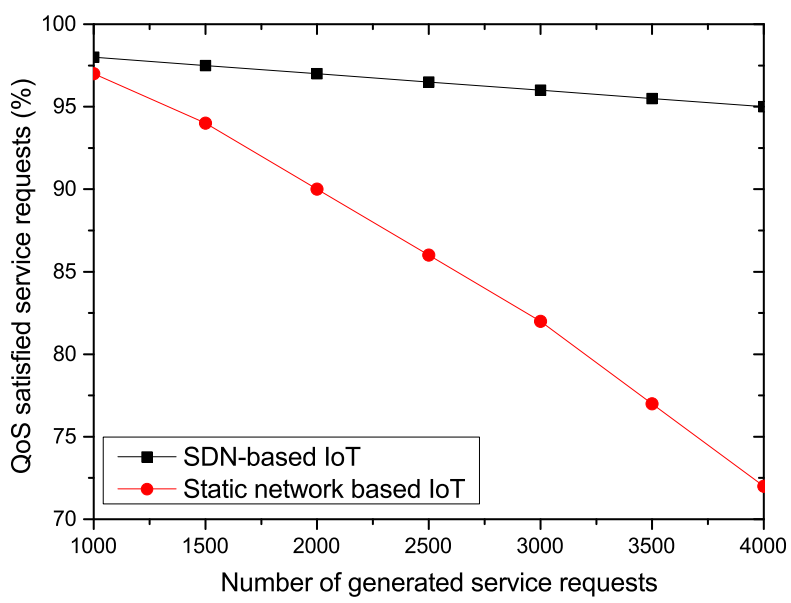

Figure 3. Percentage of $\mathrm{Q}_{0} \mathrm{~S}$ satisfied service requests vs number of service requests 
remains in high. How ever, a very less amoun t of downfall in the percen tage of QoS satisfie service request is also experienced in SDN-based IoT as the number of service request rises. It happens due to runtime activ ation of idle Fog nodes to meet the service demand. The required time for activ ating an idle Fog node has adverse effect of the QoS satisfie service delivery of some requests.

\section{Conclusion}

The domain of IoT is expanding at a great pace. It is also experiencing different type of challeng es in its way of practical applicability. We have targ eted one of such challeng es of IoT in respect of scalable resource discovery. Here, the proposed SDN-based resource discover policy for IoT uses contextual information of computa tional entities, netw orks and IoT devices to iden tify suitable resources and routing path to process and forward IoT-data. The policy is independen $t$ of increasing number of data processing (service) requests that comes from geo-distributed IoT-devices. In consequence, the policy facilita tes scalable resource discov ery in IoT. Moreover, several simula tion studies also claim the feasibility of the proposed policy in respect of resource discov ery time and QoS satisf action rate of service requests. The SDN-based solution is substan tiall y efficient compared to the static netw ork based resource discov ery for IoT.

In future we aim at extending SDN-based solutions to other aspects of IoT such as SDN-based IoT netw ork manag emen $t, S D N$-assisted conten $t$ distribution in IoT, applica tion depl oymen $\mathrm{t}$ in SDN-enabled IoT.

\section{References}

[1] Qin, Y., Sheng, Q.Z., Falkner, N.J.G., Dustdar, S., Wang, H. and Vasilakos, A.V. (2014) When things matter: A data-cen tric view of the internet of things. CoRR abs/1407.2704. URL http://arxiv.org/abs/ 1407.2704.

[2] Liu, J., Li, Y., Chen, M., Dong, W. and Jin, D. (2015) Softw are-define internet of things for smart urban sensing. IEEE Communications Magazine 53(9): 55-63. doi: 10.1109/MC OM.2015.7263373

[3] Kirkpatrick, K. (2013) Softw are-define netw orking. Commun. ACM 56(9): 16-19.

[4] Govindarajan, K., Meng, K.C., Ong, H., Tat, W.M., Sivanand, S. and Leong, L.S. (2014) Realizing the quality of service (qos) in softw are-define netw orking (sdn) based cloud infrastructure. In 2014 2nd International Conference on Information and Communication Technology (ICoICT): 505-510.

[5] Zhang, Y., Shen, Y., Wang, H., Yong, J. and Jiang, X. (2016) On secure wireless communications for iot under eavesdropper coll usion. IEEE Transactions on Automation Science and Engineering 13(3): 1281-1293. doi: 10.1109/T ASE.2015.2497663
[6] Yen, T.C. and Su, C.S. (2014) An sdn-based cloud computing architecture and its mathematical model. In 2014 International Conference on Information Science, Electronics and Electrical Engineering, 3: 1728-1731.

[7] Ku, I., Lu, Y. and Gerla, M. (2014) Softw are-define mobile cloud: Architecture, services and use cases. In 2014 International Wireless Communications and Mobile Computing Conference (IWCMC): 1-6.

[8] Gudipati, A., Perry, D., Li, L.E. and Katti, S. (2013) Softran: Softw are define radio access netw ork. In Proceedings of the Second ACM SIGCOMM Workshop on Hot Topics in Software Defined Networking, HotSDN '13 (New York, NY, USA: ACM): 25-30. doi: 10.1145/2491185.2491207 URL http://doi .acm.org/10.1145/2491185.2491207.

[9] Yeganeh, S.H., Tootoonchian, A. and Ganjali, Y. (2013) On scalability of softw are-define netw orking. IEEE Communications Magazine 51(2): 136-141.

[10] Jararweh, Y., Al-Ayyoub, M., Darabseh, A., Benkhelifa, E., Vouk, M. and Rindos, A. (2015) Sdiot: a softw are define based internet of things framew ork. Journal of Ambient Intelligence and Humanized Computing 6(4): 453461.

[11] Wu, D., Arkhipov, D.I., Asmare, E., Qin, Z. and McCann, J.A. (2015) Ubif ow: Mobility manag emen $t$ in urban-scale softw are define iot. In 2015 IEEE Conference on Computer Communications (INFOCOM): 208-216.

[12] Mahmud, M.R., Afrin, M., Razzaque, M.A., Hassan, M.M., Alelaiwi, A. and Alrubaian, M. (2016) Maximizing quality of experience through context-aware mobile applica tion sched uling in cloudlet infrastructure. Software: Practice and Experience 46(11): 15251545. doi: 10.1002/spe.2392, URL http://dx.doi.org/ 10. 1002 / spe.2392. Spe.2392.

[13] D. Silva, M.P., NazÃąrio, D.C., Dantas, M.A.R., GonÃĞalves, A.L., Pinto, A.R., Manerichi, G. and Vanelli, B. (2016) Context manag emen $t$ and distribution architecture using softw are-define netw orking. In 2016 IEEE 25th International Conference on Enabling Technologies: Infrastructure for Collaborative Enterprises (WETICE): 185-190.

[14] Savarese, G., Vaser, M. and Ruggieri, M. (2013) A softw are define netw orking-based context-aware framew ork combining $4 \mathrm{~g}$ cell ular netw orks with $\mathrm{m} 2 \mathrm{~m}$. In 2013 16th International Symposium on Wireless Personal Multimedia Communications (WPMC): 1-6.

[15] Afrin, M., Mahmud, M.R. and Razzaque, M.A. (2015) Real time detection of speed breakers and warning system for on-road drivers. In 2015 IEEE International WIE Conference on Electrical and Computer Engineering (WIECON-ECE): 495-498. doi:10.1109/WIEC ONECE.2015.7443976

[16] Gupta, H., Vahid Dastjerdi, A., Ghosh, S.K. and Buyya, R. ifogsim: A toolkit for modeling and simulation of resource manag ement techniques in the internet of things, edge and fog computing environmen ts. Software: Practice and Experience doi: 10.1002/spe.2509 . Spe.2509. 